\title{
Design and implementation of high frequency induction heating with LLC resonant load matching using ELTA
}

\author{
Suganthi Karuppusamy ${ }^{1}$, Sunandhitha $V^{2}$, Suraj $\mathbf{R}^{3}$, Roja T $\mathrm{S}^{4}$, Sundararaman $\mathrm{K}^{\mathbf{5}}$ \\ 1,2,3,4 Department of Electrical and Electronics Engineering, Sri Venkateswara College of Engineering, India \\ ${ }^{5}$ Department of Electrical and Electronics Engineering, Rajalakshmi Institute of Technology, India
}

\begin{tabular}{l}
\hline Article Info \\
\hline Article history: \\
Received Aug 5, 2018 \\
Revised Mar 1, 2019 \\
Accepted Aug 20, 2019 \\
\hline
\end{tabular}

Keywords:

ELTA

Impedance matching

Induction heating

LLC resonant converter

SiC MOSFET

\begin{abstract}
Induction heating is a non-contact method of producing heat which can be used to perform various processes like hardening, annealing, tempering, welding, brazing, melting, forging, etc. This paper discusses the design and implementation of induction heating on a given work-piece, using an LLC resonant circuit and a transformer for impedance matching, so as to transfer a maximum power of $5 \mathrm{KW}$ to the load. The load parameters are found out using ELTA software which calculates the values based on the dimensions of the work piece, operating frequency and temperature. The inverter used is based on SiC MOSFETs which minimizes the losses at high frequencies and high temperatures. The theoretical and simulated results from MATLAB are analysed and verified. The hardware is implemented for the LLC circuit with transformer and the results are presented.
\end{abstract}

This is an open access article under the CC BY-SA license.

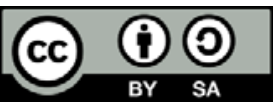

\section{Corresponding Author:}

Suganthi K,

Departement of Electrical and Electronics Engineering,

Sri Venkateswara College of Engineering,

Sriperumbudur, Chennai 602 117, Tamil Nadu.

Email:suganthi@svce.ac.in

\section{INTRODUCTION}

Induction heating is the most clean, efficient, cost-effective, precise, and repeatable method of material heating available to the industry, today. It works on the principle of Faraday's law of electromagnetic induction. The purpose of induction heating maybe to harden a part to prevent wear; make the metal plastic for forging; braze or solder two parts together; or for any number of other applications [1].

Resonant power converters are widely used for induction heating and they usually operate at several tens of $\mathrm{KHz}$ to the $\mathrm{MHz}$ range. The selection of ideal frequency for induction heating of a particular application is discussed in [2]. The power range varies from kilowatts in domestic and medical applications to several megawatts in industrial applications. These designs imply challenges pertaining to blocking voltages, switching losses, and operation in harsh environments that perfectly match the features of SiC devices, opening the design window to high performance converters and innovative industrial heating applications. Silicon carbide ( $\mathrm{SiC}$ ) power devices have been investigated extensively in the past two decades. A review of the various technological progress of $\mathrm{SiC}$ power devices and their emerging applications is presented in [3].SiC Mosfet devices also have the capability to significantly expand the voltage range over what is already available with $\mathrm{Si}$ power devices.SiC switches would operate over higher voltage and temperature ranges, and yet have sizes nearly 20 times smaller than that of Si-based devices. They are also considered to be superior in terms of high temperature stability, low loss in operation and fast switching time over the conventional Si switches [4, 5]. 
The coil used for induction heating has apart from reactance, a small resistance also. A change in coil resistance and reactance results in a change in power factor $(\operatorname{Cos} \Phi)$ and quality factor, $\mathrm{Q}$. When we analyse the output power characteristic versus the circuit operating frequency for a given load circuit, it is seen that the output power varies widely with the operating frequency. The goal is to deliver the required power to heat the workpiece without exceeding any of the power source parameters. The various advantages and disadvantages of using an LLC resonant converter is discussed in [6] and an equivalent model is presented in [7]. The LLC configuration offers a better performance than the conventional series resonant inverter (SRI), due to it's short-circuit immunity and low transformer secondary current. An optimized design for a LLC resonant converter for the required output power capacity is presented in [8]. When compared to the SRI, the LLC configuration involves the inclusion of a new reactive element Ls and the overdimensioning of the capacitance. But these drawbacks are overcome at high frequencies as Ls could be a parasitic inductance and the current gain value minimizes the capacitance increment.

The optimum selection of resonant tank circuit and a modified LLC load resonant circuit configuration of a full bridge inverter for induction heating applications are discussed in [9]. The three tank circuits - series, parallel and LLC tank circuits are compared based on their performance and characteristics. The series tank circuit requires a matching transformer when used for induction heating. In the case of a parallel resonant circuit, efficiency is reduced at light loads. LLC resonant circuit results in increased system efficiency with less weight and size of the power supply and is generally preferred over a series or parallel resonant converter.

When LLC resonant circuit is used with a transformer, the magnetizing inductance of the transformer is also considered as one of the inductances. This needs to be small, requiring larger current through the switches and consequent losses. In [10] is suggested an alternative configuration suitable for wide input voltage and load ranges but this requires two resonant tanks and auxiliary switches. An asymmetrical voltage cancellation technique with an LLC resonant converter for induction heating is suggested in [11] where the duty cycle is varied with PLL control tracking the resonant frequency. A complete procedure for simulation, analysis and design criteria for a LLC resonant converter is discussed in [12] and [13].

The load matching technique which has to be done for high frequency induction heating can be done by various methods as discussed in [14-16]. The conventional method of using a transformer for load matching can be replaced by an LLC circuit. The usage of transformer for load matching has its advantages and disadvantages. A resonant converter using $\mathrm{SiC}$ Mosfets in a half-bridge configuration but at a lower power level of $650 \mathrm{~W}$ is discussed in [17]. A SiC based converter with soft switching and using an interleaved boost converter is proposed in [18]. An approach to identify the resonant tank elements is suggested in [19].

This paper studies a configuration which is a combination of an LLC circuit in addition to a transformer. In an industrial environment, apart from the converter and the matching transformer, the design of the induction coil and its profile itself is critical to obtain the best performance. A systematic design procedure for the coil is essential for proper matching of the converter with the coil. Induction coil design using ELTA and 2DELTA software is illustrated in [20-23] with and without converters.

The main objective of this paper is to perform surface hardening on the given work-piece with a $5 \mathrm{KW}$ resonant inverter which uses $\mathrm{SiC}$ switches in a combination of LLC resonant circuit with a transformer and using ELTA software for coil design.

\section{COIL DESIGN USING ELTA}

ELTA (Electro Thermal Analysis) software is used to simulate the induction heating system [24]. The electrical parameters of the converter are selected using this software. The type of material used for the workpiece, the geometry of the coil and the geometry of the workpiece are specified in the software. The characteristics of the load on the inverter is evaluated using ELTA software and the waveforms are obtained for power, voltage, impedance, inductance, temperature and power factor with respect to time. The equivalent inductance and equivalent resistance values are found out from this software and are used for further calculations in designing the circuits.

The workpiece parameters such as size of the work piece, material used and the processing parameters like temperature, length of the system, etc are entered in the dialog box shown in Figure 1 and Figure 2 respectively. ELTA does the simulation and gives the graphical and numerical outputs of the load and coil parameters.

Design and implementation of high frequency induction heating with LLC ... (Suganthi Karuppusamy) 


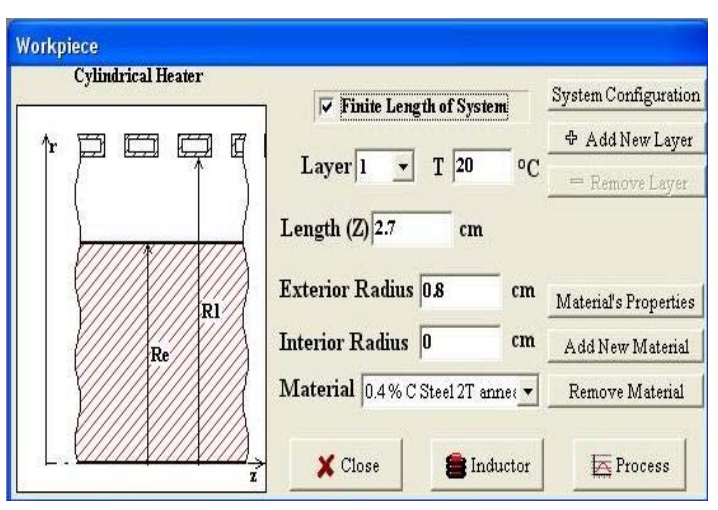

Figure 1.Workpiece dialog box

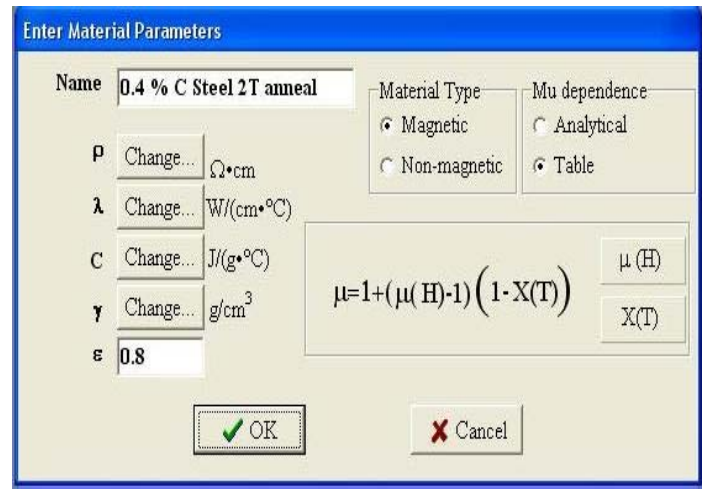

Figure 2. Material parameters dialog box

\subsection{Coil parameters}

Figure 3 shows the inductor dialog box and using this, the coil specification such as the radius, number of turns, resistivity and length of the coil are specified. The thermal insulation on the coil if needed can also be mentioned. The tube profile dialog box can be used to specify the shape and size of the coil.

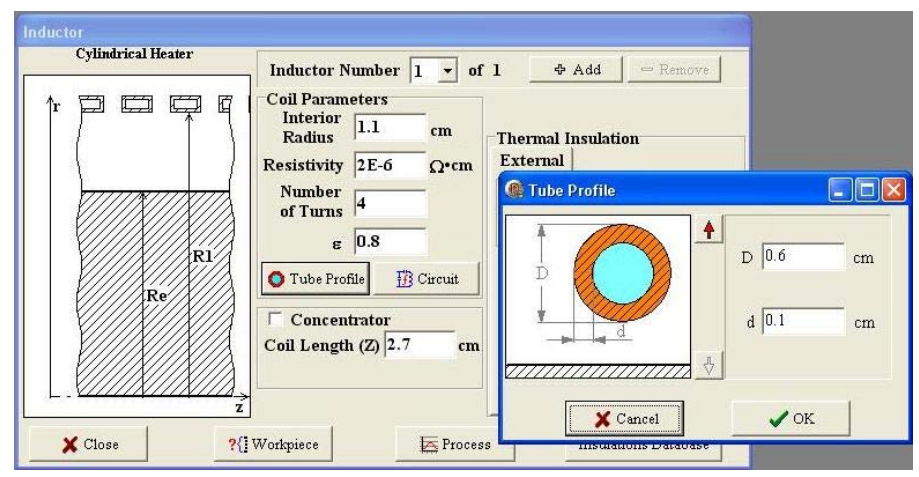

Figure 3. Inductor dialog box

Circuit dialog box shown in Figure 4 can be used to choose the circuit type i.e. series or parallel, number of leads and geometry of the lead. Also the processing dialog box shown in Figure 5 is used to specify the type of processing such as heating or cooling and whether the supply constitutes current, voltage or power, the working frequency, current, duration of the process, type of cooling, etc.

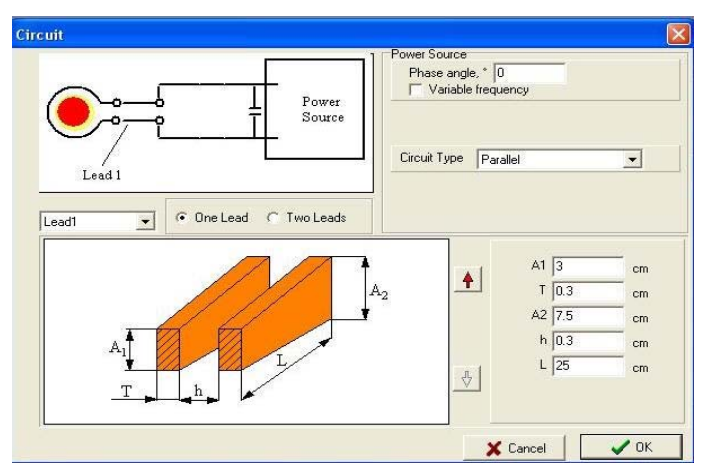

Figure 4. Circuit dialog box

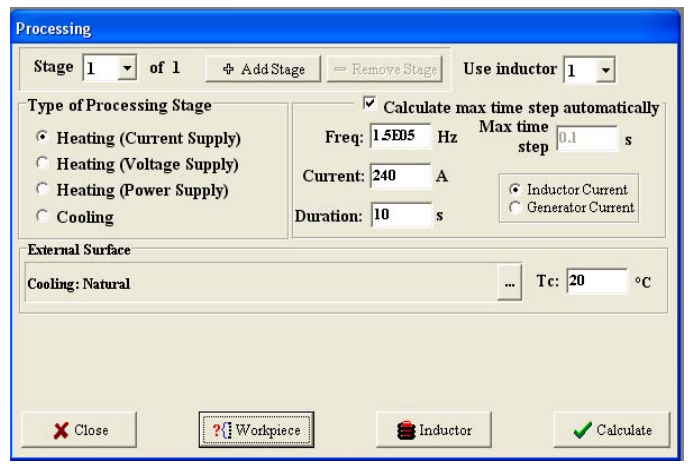

Figure 5. Process dialog box 


\subsection{Results obtained from ELTA}

Hardware design is based on results obtained from ELTA. In this software, the total heating time is divided into a large number of small increments in time. After each step, the material characteristics, which depend upon the temperature achieved, are evaluated. The calculation is extended till the end of the target time. The software provides us with waveforms of different parameters.

Figure 6 below shows the graph of the impedance vs time characteristics. The impedance peaks when the material is magnetic and when the resistivity is high. As the material becomes non-magnetic, the impedance drops. Inductance vs time waveform is shown in Figure 7. The inductance peaks when the material is magnetic and when the resistivity is high. Also, the material becomes non-magnetic when the inductance drops. Thus, from the results obtained, the coil inductance is taken to be $180 \mathrm{nH}$.

Figure 8 represents the graph of voltage vs time. The voltage also peaks when the material is magnetic and when the resistivity is high. As the material becomes non-magnetic the voltage drops. Figure 9 represents the curve between power and time. Like the impedance, inductance and voltage, power also peaks when the material is magnetic, and resistivity is high. When the material becomes non-magnetic, the power drops. All these projections are based on the assumption that the current through the coil is constant. It is also possible to evaluate the load with constant applied voltage to the coil or constant power.

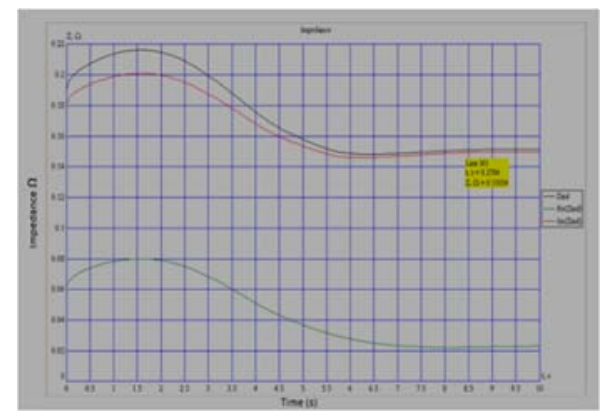

Figure 6. Impedance waveform

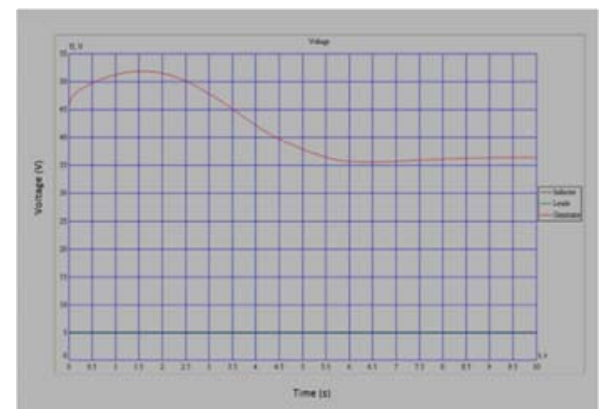

Figure 8. Voltage waveform

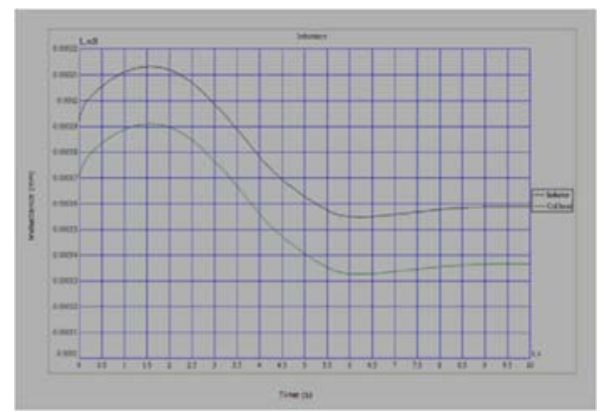

Figure 7. Inductance waveform

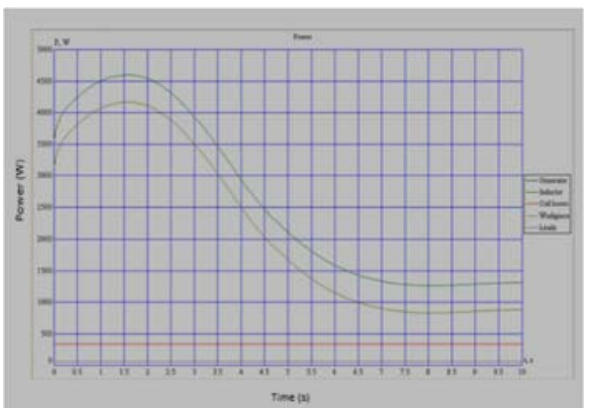

Figure 9. Power waveform

\section{DESIGN OF POWER CIRCUIT}

The topology shown in Figure 10 is that of an LLC circuit with transformer. A transformer is connected between the series inductor and capacitor. A DC blocking capacitor is used to filter high frequency components passing through the transformer. From the ELTA software, the value of load inductance is found to be $180 \mathrm{nH}$. The quality factor according to the industry standards is in the range of 3 to 10 and is assumed to be 5.4 . 


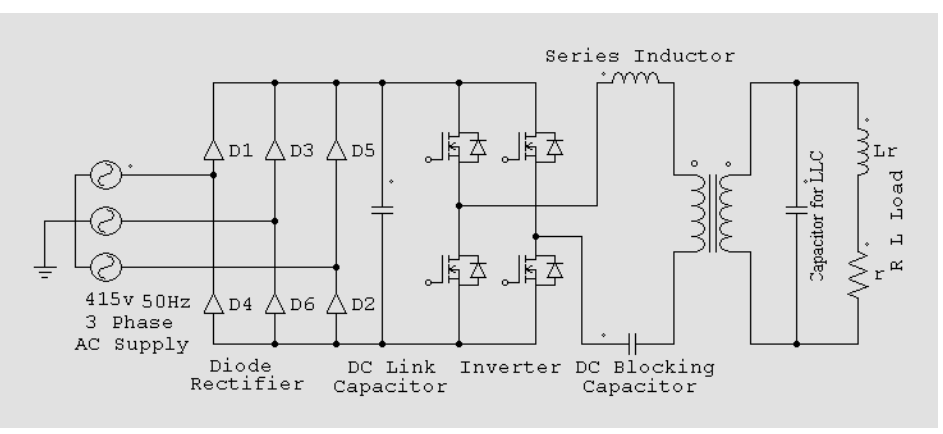

Figure 10. LLC circuit with transformer $\mathrm{V}=400 \mathrm{~V}$

The design calculations are as follows: $\mathrm{P}=5 \mathrm{KW}, \mathrm{Q}=5.4, \mathrm{~L}_{\mathrm{r}}=180 \mathrm{nH}, \mathrm{f}=150 \mathrm{kHz}, \varphi=35^{\circ}$,

Value of the first harmonic, $U_{d c}=1.3 * 400=520 \mathrm{~V}$

$V_{\text {in }}=\frac{4 * V * 1.3}{\pi}=\frac{4 * 400 * 1.3}{\pi}=662.085 \mathrm{~V}$ given by

The ratio of the load inductance to the series inductance in a LLC circuit is defined as $\beta$ and is

$$
\beta=Q * \tan (\varphi)-1=5.4 * \tan (35)-1=2.781
$$

Load Resistance, $R_{S}=2 \pi f \frac{L_{r}}{Q}=2 \pi * 150000 * \frac{180 * 10^{-9}}{5.4}=0.031416=31.416 \mathrm{~m} \Omega$

LLC circuit parameters are calculated using the equivalent series resonant circuit procedure discussed in [6].

The calculations from SRI circuit to LLC resonant circuit (Figure 11) are carried out as follows:

capacitance of the series oscillator, $C_{s r i}=\frac{1}{4 \pi^{2} f^{2} L_{r}}=\frac{1}{4 \pi^{2} * 150000^{2} * 180 * 10^{-9}}=6.254 \mu \mathrm{F}$

capacitance of LLC oscillator, $\mathrm{C}=\frac{(\beta+1) C_{s r i}}{\beta}=\frac{(2.781+1)\left(6.25 * 10^{-6}\right)}{2.781}=8.497 \mu \mathrm{F}$

transformation ratio of SRI, $N_{1}=\frac{V_{\text {in }}}{\sqrt{2 * P * R_{S}}}=\frac{662.085}{\sqrt{2 * 5000 * 0.031416}}=37.354$

transformation ratio of LLC, $N_{p}=\frac{N_{1}}{\beta}=\frac{37.354}{2.781}=13.431$

series inductance in primary, $L_{s}=N_{p}{ }^{2} * L_{s 2}=90.376 \mu \mathrm{H}$

resonant frequency, $f_{0}=\frac{1}{2 \pi \sqrt{C *\left(L_{r} * \frac{L_{S 2}}{L_{r}+L_{S 2}}\right)}}=149.727 \mathrm{~Hz}=150 \mathrm{kHz}$

maximum voltage across the capacitor, $V_{c \max }=\frac{Q * V_{i n}}{N_{p} * \beta}=95.719 \mathrm{~V}$

peak current in the inverter, $I_{p}=\frac{2 P}{V_{i n} * \cos (\varphi)}=18.438 \mathrm{~A}$

Figure 12 shows the MATLAB simulation and Figures 13 and 14 show the simulation results of of LLC with transformer inverter output voltage and load current waveforms respectively. Design and simulation is also carried out without a transformer with only an LLC circuit. While using a transformer, the $\beta$ value is 2.781 and the power factor wa 0.81 whereas the power factor of LLC circuit without the transformer is 0.1 with the $\beta$ value of 22.47 . By using transformer, the value of $\beta$ decreases and the power factor increases which in turn increases the efficiency. 

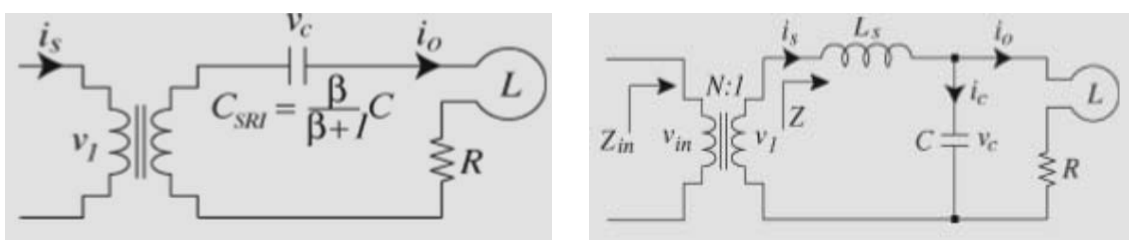

Figure 11. SRI to LLC resonant circuit conversion

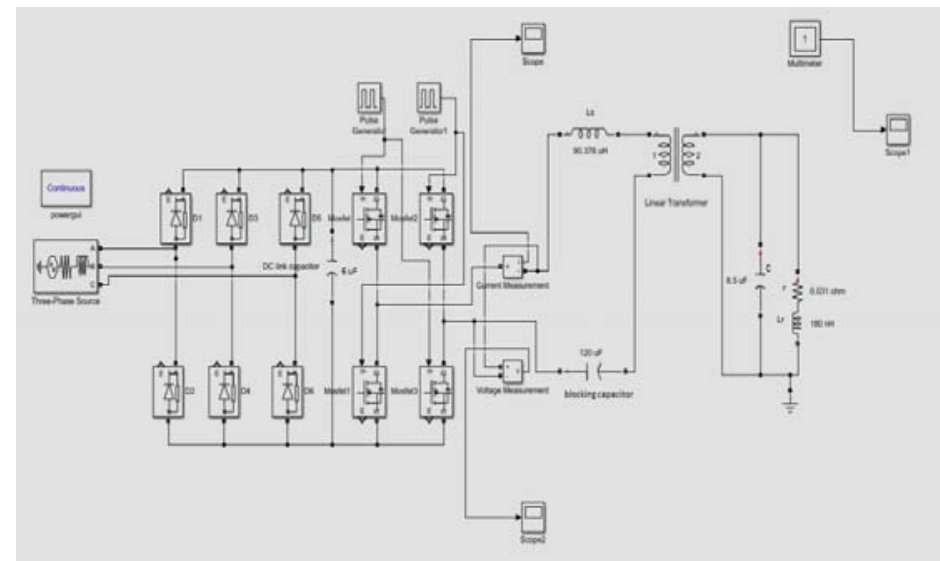

Figure 12.Simulation of LLC circuit with transformer using MATLAB

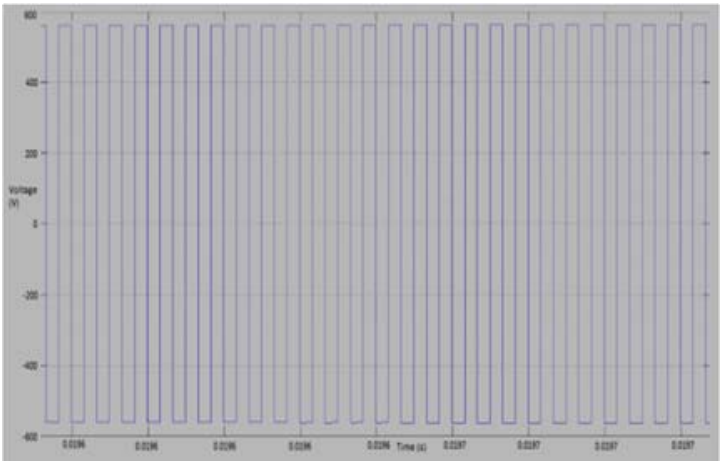

Figure 13. Inverter output voltage

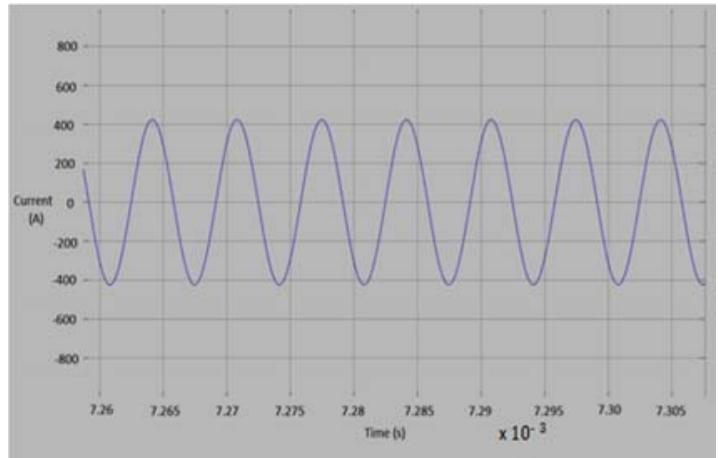

Figure 14. Load output current waveform

\section{HARDWARE IMPLEMENTATION}

Table 1 shows the specifications used for the required load.

Table 1. Hardware specifications

\begin{tabular}{clc}
\hline S. No. & Description & Value \\
\hline 1. & Line Voltage & $415 \mathrm{~V}$ \\
2. & Supply Frequency & $50 \mathrm{~Hz}$ \\
3. & Operating Frequency & $150 \mathrm{~Hz}$ \\
4. & Coil current (assumed) & $240 \mathrm{~A}$ \\
5. & Quality Factor & 5.4 \\
6. & Phase Angle & 35 \\
7. & Output power required & $5 \mathrm{~kW}$ \\
8. & Load inductance & $180 \mathrm{nH}$ \\
\hline
\end{tabular}


- $\quad$ Inverter power $=5 \mathrm{KW}$

- $\quad$ Typical inverter efficiency $(\eta)=0.9$

- $\quad$ Typical power factor at input $=0.93$

KVA demand at input $=$ Inverter power $/(\eta *$ power factor $)=\frac{5}{0.9 * 0.93}=5973.7 \mathrm{VA}$

- $\quad$ Line voltage $=415 \mathrm{~V}, 3$-phase

Line current $=\frac{5973.7}{\sqrt{3} * 415}=8.31 \mathrm{~A}$

\subsection{Hardware components}

Figure 15 shows the induction heating of load using hardware setup. It may be noted that for the experimental setup, various hardware items were provided by M/s GH Induction India Private Limited [25] from their general stocks and these items may have no relation to the actual working conditions.Line choke with the inductance value of $3.2 \mathrm{mH}, 10 \mathrm{~A}$ was used. A rectifier module SKKD 101/16 rated for 1600V, 100A was used. DC link capacitors of film and foil construction was used so that the equivalent series resistance (ESR) will be low. Four numbers of $3 \mu \mathrm{F}$ capacitors were used. Resistors encapsulated in aluminium heat sinks were used for initial charging of the DC link capacitors and discharging the capacitors when the unit was switched off. Four resistors with rating $330 \Omega, 25 \mathrm{~W}$ and SiC Mosfets CAS300M12BM2 were used. Air cooling was used in the design to avoid water cooling. Extruded aluminium heat sink with two small fans mounted at one end was used for cooling the MOSFETs.

The DC blocking capacitors at the output of the inverter are supposed to have a low reactance at the operating frequency and at the same time, prevent the short circuit of the inverter voltage by the load. The DC blocking capacitor is also expected to carry the inverter current at high frequency. A DC blocking capacitor of $60 \mu \mathrm{F}$ was used.

From the calculations, a ferrite core matching transformer with a turns ratio of 15:1 was used for operating at a frequency of $150 \mathrm{kHz}$, the primary voltage and current rating being $560 \mathrm{~V}$ and $11 \mathrm{~A}$ respectively. The inductance of the load coil which was estimated as $180 \mathrm{nH}$ in the simulation software, turned out tobe $260 \mathrm{nH}$ in the practical realization. The capacitor required for resonance was $8.5 \mu \mathrm{F}$. The capacitor was selected based on current carrying capacity at the operating frequency. From the SRI to LLC design calculation, the value of the series inductor selected was $90 \mu \mathrm{H}$. To make the unit compact, it was decided to employ ferrite cores to assemble the inductor. Standard available cores were used thus leading to a disproportionately large looking series reactor. An image of the work piece getting induction heated is shown in Figure 15.

The impedance curve of the LLC inverter has two resonant frequencies. One higher frequency where the series resonance takes place, and another lower frequency where parallel resonance takes place. The LLC inverter generally operates at a frequency above the series resonant frequency, in the "inductive" mode. At the series resonant frequency, the impedance is the lowest and the power is the highest. The power is controlled by sweeping the frequency from a high value to a low value approaching the resonant frequency.

The control card implements the following loops: (i) To sweep the switching frequency towards the resonant frequency as required to meet the target power. A PLL and a VCO are used for frequency correction. (ii) To ensure that the switching of the MOSFETs would be done only at the zero crossing of the inverter current or close to the zero crossing, (iii) To maintain a dead time between the driving pulses for the two channels providing safety against short circuit.

The control block diagram is shown in Figures 16, Figure 17 and Figure 18. For the control of a SRI, the phase angle between the inverter voltage and the inverter current is employed. However, for the LLC inverter the angle between the inverter voltage and the capacitor voltage is also measured for applying a limit. This angle is defined as $\alpha$. In our project the standard control card of a SRI was employed, supplemented by another card to measure the angle alpha.

The power control of both the SRI and the LLC inverter are implemented by frequency modulation. The pulses representing the inverter voltage are taken from the driver section of the main control card. The pulses representing the capacitor voltage are received through a fibre optic link from the card one mounted close to the capacitor.

Int J Pow Elec \& Dri Syst Vol. 11, No. 1, Mar 2020 : 178 - 188 

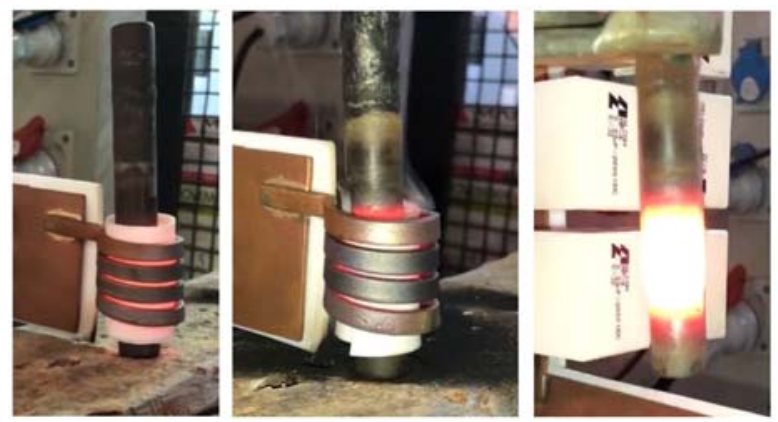

Figure 15. Induction heating of load using hardware

\subsection{Hardware results}

Figures 19 and 20 show the $415 \mathrm{~V}, 50 \mathrm{~Hz}$ AC supply voltage waveform and 600V inverter input DC voltage respectively. Figure 21 shows that the inverter output voltage which is obtained as 560V.The inverter current waveform obtained in Figure 22 is taken at higher load condition.In Figure 23, the two arms of the bridge are not "ON" simultaneously. The dead time when both the MOSFETs are off is measured to be $240 \mathrm{~ns}$ as in Figure 24. The tank voltage waveform across the capacitor showing both the frequency and amplitude is shown in Figure 25 (a) and (b) respectively.

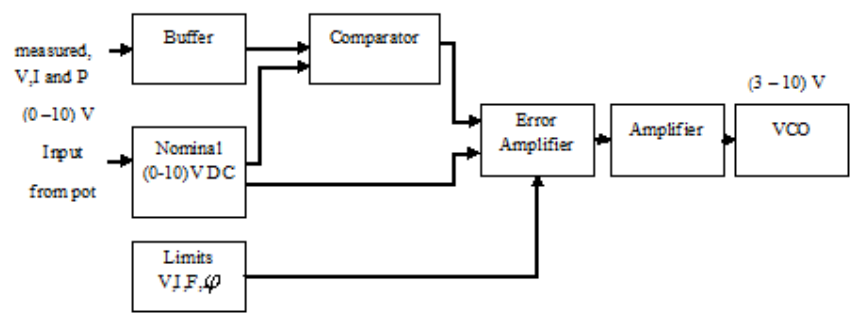

Figure 16. Block diagram of main control card

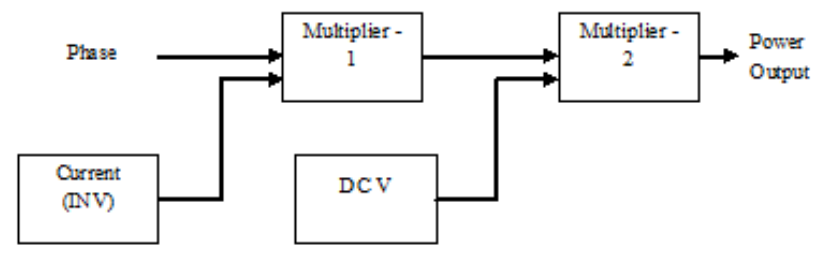

Figure 17. Block diagram of power calculation

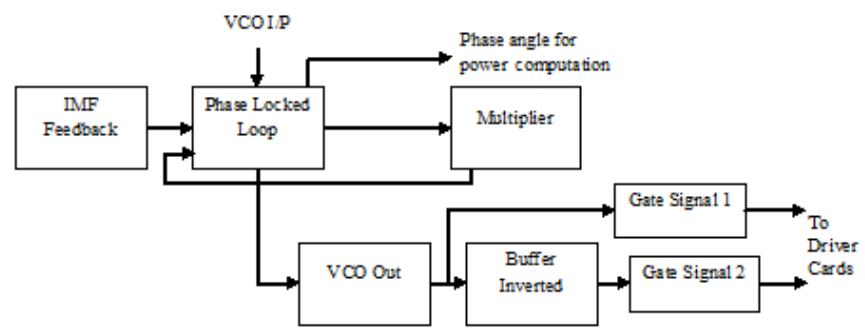

Figure 18. Block diagram of frequency control 


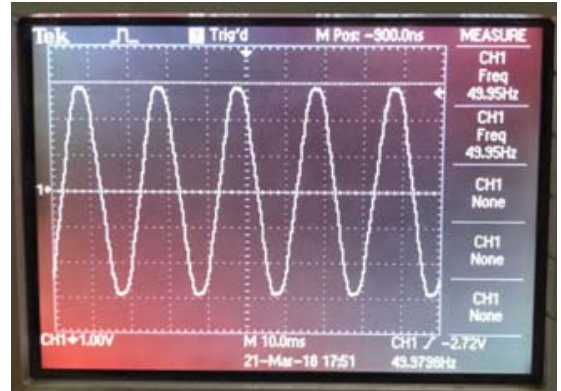

Figure 19.Line voltage waveform

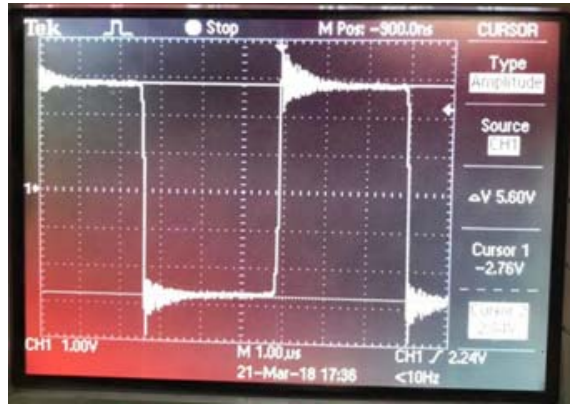

Figure 21.Inverter voltage waveform

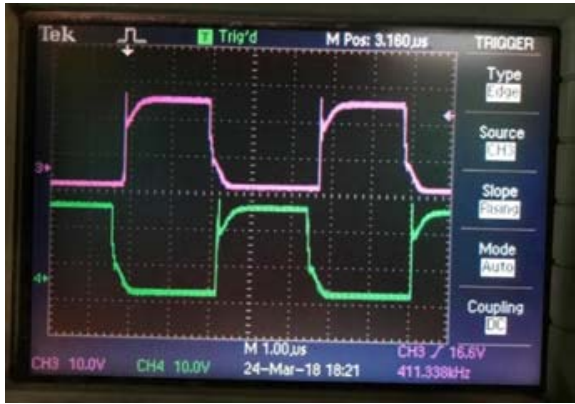

Figure 23.Drive pulses - two instances

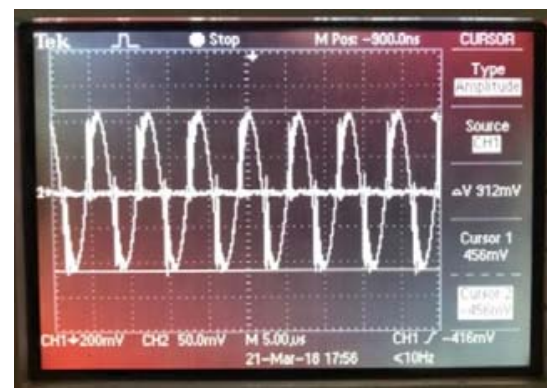

(a)

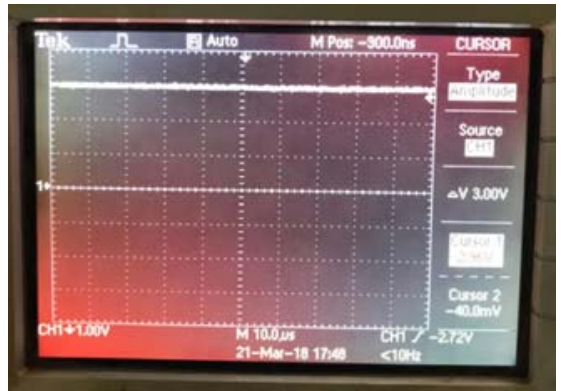

Figure 20. DC voltage waveform

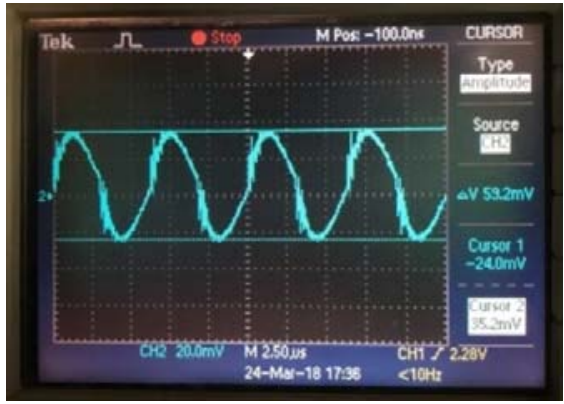

Figure 22. Inverter current waveform

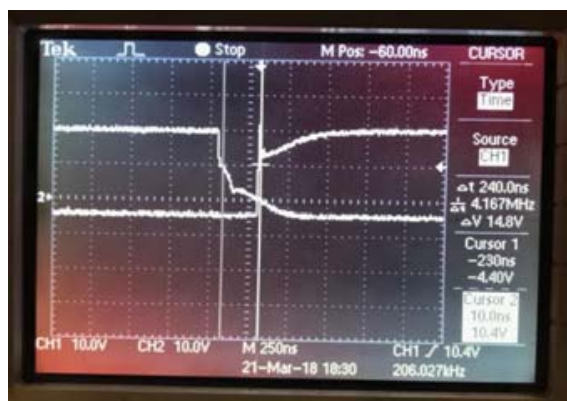

Figure 24. Dead time

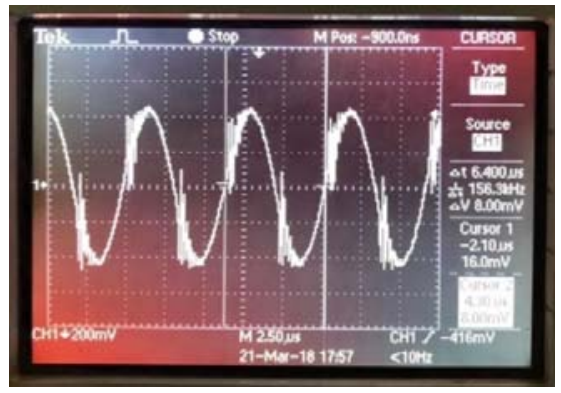

(b)

Figure 25. Tank voltage waveform displaying the (a) frequency (b) amplitude 
Measurement of phase angle is shown in Figure 26a and b.The current waveform looks triangular as the load is small.

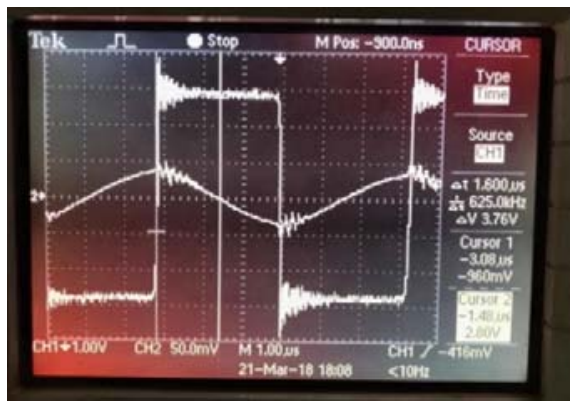

(a)

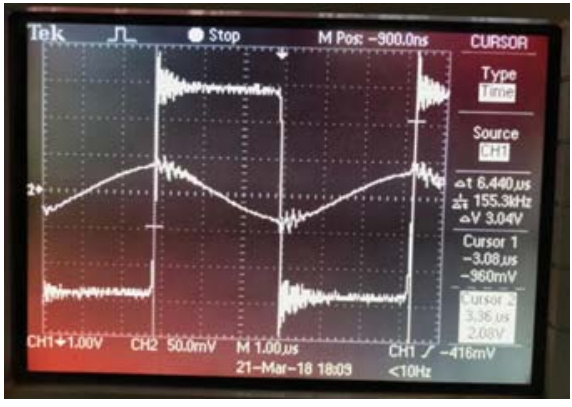

(b)

Figure 26. Phase angle measurement with (a) $t_{1}$ (b) $t_{2}$

$$
\mathrm{t} 1=1.6 \mu \mathrm{s}, \mathrm{t} 2=6.4 \mu \mathrm{s} ; \phi=\frac{t 1}{t 2} \times 360=\frac{1.6}{6.4} \times 360=90^{\circ}
$$

\section{COMPARISION OF THEORETICAL, SIMULATION AND EXPERIMENTAL VALUE}

A comparison of theoretical, simulated and hardware results in Table 2 shows broad agreement.

Table 2. Comparision of theoretical, simulation and experimental values

\begin{tabular}{cccc}
\hline Parameter & Theoretical value & Simulation value & Hardware value \\
\hline Inverter output current & $18.44 \mathrm{~A}$ & $13 \mathrm{~A}$ & $14.8 \mathrm{~A}$ \\
Inverter output voltage & $520 \mathrm{~V}$ & $580 \mathrm{~V}$ & $560 \mathrm{~V}$ \\
Inverter output power & $5 \mathrm{~kW}$ & $4.32 \mathrm{~kW}$ & $4.75 \mathrm{~kW}$ \\
Load output voltage & $95.719 \mathrm{~V}$ & $92 \mathrm{~V}$ & $91.2 \mathrm{~V}$ \\
\hline
\end{tabular}

\section{CONCLUSION}

The proposed method of load matching using a combination of an LLC resonant circuit and a transformer meets the high frequency induction heat treatment requirements. The load parameters are evaluated using ELTA software. The power factor of LLC circuit without a transformer is found to be 0.1 whereas that with a transformer is 0.81 . Thus, this method improves the power factor and in turn, the efficiency. Also, the use of $\mathrm{SiC}$ switches in place of conventional Si switches enables to carry out induction heating at higher frequencies and in circuits with higher operating voltages.

\section{ACKNOWLEDGEMENTS}

This work is sponsored by M/S GH Induction India Pvt. Ltd and is done as a final year project. We wish to record our deep gratitude to the company and to its Vice Chairman, Mr.V.R.Chari for all the support and assistance.

\section{REFERENCES}

[1] O. Lucía, P. Maussion, E. Dede, and J. M. Burdío, "Induction heating technology and its applications: Past developments, current technology, future challenges," IEEE Trans. Ind. Electron., vol. 61, No. 5, pp. 2509-2520, 2014.

[2] N.R. Stansel, "Induction heating- Selection of frequency," Electrical Engineering, vol. 63, No. 10, 1944.

[3] Xu She, Alex Q. Huang, Oscar Lucia, and BurakOzpineci, "Review of Silicon Carbide Power Devics and their Applications," IEEE Transactions on Industrial Electronics, vol. 64, No. 10, 2017.

[4] Alvin ong, Joseph Carr, Juan Balda, and Alan Mantooth, "A Comparison of Silicon and Silicon Carbide MOSFET Switching Characteristics," 2007 IEEE Region 5 Technical Conference, 2007.

[5] Helong Li and StigMunk-Nielsen "Detail Study of SiC MOSFET Switching Characteristics," 2014 IEEE 5th International Symposium on Power Electronics for Distributed Generation Systems (PEDG), 2014. 
[6] Jose M. Espi-Huerta, Enrique J. Dede Garcia Santamaria, RafaelGarcia Gill, and Jaime Castello-Moreno, "Design of the L-LC Resonant Inverter for Induction Heating Based on its Equivalent SRI," IEEE Transactions on Industrial Electronics, vol. 54, No. 6, 2007.

[7] ShuilinTian, Fred C.Lee, Qiang Li, "Equivalent Circuit Modeling of LLC Resonant Converter," 2016 IEEE Applied Power Electronics Conference and Exposition (APEC), 2016.

[8] Michael Frivaldsky, JozefKandrac, and PavolSpanik, "Optimized Design of the main circuit of LLC Converter for high frequency application," 2010 International Conference on Applied Electronics, 2010.

[9] M. K. Rajaram and N. Booma, "Resonant inverter for induction heating", International Conference on Computing, Electronics and Electrical Technologies [ICCEET], 2012.

[10] Bong-Gun Chung, Kwang-Ho Yoon, SopheakPhum, Eun-Soo Kim, and Jong-Seob Won, "A Novel LLC Resonant Converter for Wide Input Voltage and Load Range," IEEE 8th International Conference on Power Electronics. pp. 2825-2830, Jeju, 2011.

[11] Saichol Chudjuarjeen, AnawachSangswang, and ChayantKoompai, "An Improved LLC Resonant Inverter for Induction-Heating Applications with Asymmetrical Control," IEEE Transactions on Industrial Electronics, vol. 58, No. 7, 2011.

[12] Kaibalya Prasad Panda and Sreyasee Rout, "A Cost-effective Design and Analysis of Full Bridge LLC Resonant Converter," World Academy of Science, Engineering and Technology, vol. 10, No. 8, 2016.

[13] Ray-Lee Lin and Chiao-Wen Lin, "Design Criteria for Resonant Tank of LLC DC-DC Resonant Converter," IECON 2010 - 36thAnuual Conference on IEEE Industrial Electronics Society, pp 427-432, 2010.

[14] Li Jingang, Wang Liping, and Sun Qi,"Research on High-frequency Induction Heating Load-matched based on LLC Resonant Circuit," International Power Electronics and Applications Conference and Exposition (PEAC), 2014.

[15] D.VijayaBhaskar and N. Vishwanathan, "Full Bridge Series Resonant Inverter for Induction Cooking Application," IEEE 5th India International Conference on Power Electronics (IICPE), 2012.

[16] M.A.Maktoomi, R.Gupta, M.H.Maktoomi, M.S. Hashmi, and F.M.Ghannouchi, "A generalized multi-frequency impedance matching technique," 2016 16th Mediterranean Microwave Symposium (MMS), 2016.

[17] N.Phankong, S.Chudjuarjeen, K.Bhumkittipich, and T.Hikihara, "Half Bridge Soft Switching Resonant Converter With Silicon Carbide Power MOSFETS For Inductive Heating," 19th International Conference on Electrical Machines and Systems (ICEMS), IEEE, 2016.

[18] Hector Sarnago, Oscar Lucia, and Jose M Burdio, "Interleaved resonant boost inverter featuring SiC module for high-performance induction heating," IEEE Transactions on Power Electronics, vol. 32, No. 2, pp. 1018-1029, 2017.

[19] Hector Sarnago, Oscar Lucia, and Jose M Burdio, "A versatile resonant tank identification methodology for induction heating systems," IEEE Transactions on Power Electronics, vol. 33, No. 3, pp. 1897-1901, 2018.

[20] Vladimir A. Bukanin, Alexei E. Zenkov, and Aleksandr N. Ivanov, "Design of induction heating devices using ELTA and 2DELTA software," IEEE Conference of Russian Young Researchers in Electrical and Electronic Engineering (EIConRus), Feb 2016.

[21] Vladimir A. Bukanin, Alexei E. Zenkov, and Aleksandr N. Ivanov, "Simulation of single and dual-frequency induction hardening of steel gear using ELTA," IEEE Conference of Russian Young Researchers in Electrical and Electronic Engineering (EIConRus), Feb 2017.

[22] Goce Stefanov, Ljupco Karadzinov, and Dejan Karanfilov, "Design of power converter for induction furnaces with computer simulations," The 33rd IEEE International Convention MIPRO, May 2010.

[23] Goce Stefanov and Ljupco Karadzinov, "Phase controlled bridge converter with serial resonant load," Proceedings of 14th International Power Electronics and Motion Control Conference EPE-PEMC, 2010.

[24] [Online], Available: http://www.nsgsoft.com/products/elta

[25] [Online], Available: http:// http://www.ghinduction.com/

Int J Pow Elec \& Dri Syst Vol. 11, No. 1, Mar 2020 : $178-188$ 